\title{
Programas governamentais de formação de professores: um olhar para o PARFOR-Inglês de uma universidade pública paranaense
}

\author{
Rafael Vitória Alves ${ }^{1}$ \\ Luciana Cabrini Simões Calvo
}

\begin{abstract}
Resumo: O presente artigo traz os resultados de uma pesquisa que teve como foco de investigação o Plano Nacional de Formação de Professores da Educação Básica (PARFOR), licenciatura LetrasInglês, de uma instituição pública paranaense de ensino superior. Pretendeu-se analisar a visão de acadêmicos e formadores envolvidos no programa a respeito da formação docente inicial de Língua Inglesa (LI) proposta no mencionado programa/projeto de curso, promovendo articulações com outros estudos que se voltam à formação de professores. Esta é uma pesquisa de cunho qualitativo, que utiliza método quantitativo para parte da análise dos dados, caracterizando-se também como um estudo de caso. O corpus da investigação foi composto de questionáriosendereçados aos acadêmicos (ingressantes no ano de 2012) e formadores participantes do projeto. Os resultados evidenciaram que o programa foi de suma importância e representou uma oportunidade para os acadêmicos repensarem suas práticas. No entanto, o fato de a maioria deles não atuar como docente de LI acarretou no desacordo do seu perfil em relação às especificações do edital do programa e se caracterizou, assim, como um aspecto reticente do curso investigado. Espera-se, a partir da conclusão deste estudo, contribuir com a área de formação de professores ao investigar uma proposta governamental emergencial de formação docente.
\end{abstract}

Palavras-chave: PARFOR. Formação de professores. Língua Inglesa.

\section{Introdução}

Nos dias atuais, é muito comum ouvir falar da falta de professores em sala de aula e, também, da pouca procura por cursos de licenciatura. Tais constatações podem ser comprovadas, por exemplo, pelos dados do Censo Escolar (BRASIL, 2007) que mostram a queda no número de formandos em cursos de licenciatura e a mudança de perfil dos que buscam a profissão. De 2005 a 2006, ainda de acordo com esses dados, houve uma redução de $9,3 \%$ de alunos formados em licenciatura. A situação é mais complicada em áreas como Letras (queda de 10\%), Geografia (menos 9\%) e Química (menos 7\%).

Essa falta de professores, em consequência da reduzida busca por esses cursos, pode ser atribuída às condições de trabalho, ao baixo salário, à formação docente, às políticas de formação, à precarização e à flexibilização do trabalho docente, à violência nas escolas e à

\footnotetext{
${ }^{1}$ Mestrando em Estudos Linguísticos da Universidade Estadual de Maringá (UEM), PR, Maringá, Brasil. Email: rafaelalves92@gmail.com

${ }^{2}$ Mestre e Doutora em Estudos da Linguagem pela Universidade Estadual de Londrina. Professora do Departamento de Letras Modernas e do Programa de Pós-graduação em Letras da Universidade Estadual de Maringá. (UEM), PR, Maringá, Brasil. E-mail: cabrinisimoes@gmail.com
} 


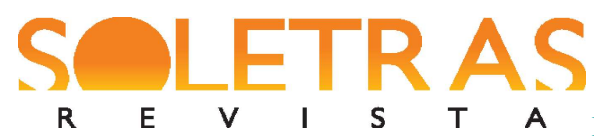

$\begin{array}{llllllll}R & \text { E } & \text { V } & \text { I } & \text { S } & \text { T } & \text { A } & \text { DOSSIÊ-N. } 35 \text { - 2018.1-RAFAEL VITÓRIA ALVES }\end{array}$

LUCIANA CABRINI SIMÕES CALVO

emergência de outros tipos de trabalho com horários parciais (GATTI et al., 2009). Todas essas questões acabam conferindo pouca atratividade aos cursos de licenciatura do ponto de vista dos jovens que estão em busca de uma profissão. E é nesse desafortunado contexto que surgem propostas de programas que visam remediar, em caráter emergencial, a escassez de docentes no ensino público do país.

Entre essas, cita-se o Plano Nacional de Formação de Professores da Educação Básica (doravante PARFOR), que faz parte da Política Nacional de Formação de Professores e foi criado para atender às regulamentações dispostas no artigo 11 , inciso III, do Decreto $\mathrm{n}^{\circ}$ 6.755, de 29 de janeiro de 2009. Esse inciso pontua que o programa deve oferecer emergencialmente cursos, tanto de licenciatura quanto para outros fins especiais, direcionados aos docentes em exercício há pelo menos três anos na rede pública da educação básica, desde que se enquadrem nestas situações: (i) graduados não licenciados; (ii) licenciados em área diversa da atuação docente; (iii) de nível médio, na modalidade normal (BRASIL, 2009).

O Programa foi lançado pelo Ministério da Educação (MEC), em parceria com a Coordenação de Aperfeiçoamento de Pessoal de Nível Superior (CAPES), tendo como principal objetivo a promoção e o fomento à oferta de educação superior, gratuita e de qualidade, para docentes em exercíciona rede pública da educação básica, conformando-os à exigência de formação estabelecida pela Lei de Diretrizes e Bases da Educação Nacional (LDB) e, por consequência, contribuindo para a melhoria da qualidade da educação básica no país (BRASIL, 2010).

Além da parceria com a CAPES, o programa trabalha em regime de colaboração com estados, municípios, Distrito Federal e Instituições de Educação Superior (doravante IES). Entre as diversas licenciaturas que o programa contempla, este estudo concentrar-se-á na de Letras, habilitação em Língua Inglesa (doravante LI), de uma IES pública paranaense.

O curso de Letras-Inglês dessa instituição é voltado para "profissionais que já possuem uma licenciatura e que atuam junto às séries do Ensino Fundamental e Médio, mas não possuem a formação específica em Letras-Inglês para tal exercício profissional" (PROJETO PEDAGÓGICO, 2011, p. 17). O seu propósito é o de habilitar os referidos profissionais para atuação nas séries supramencionadas de forma crítica e consciente, promovendo a "formação do cidadão e a socialização do conhecimento" (PROJETO PEDAGÓGICO, 2011, p. 15). 


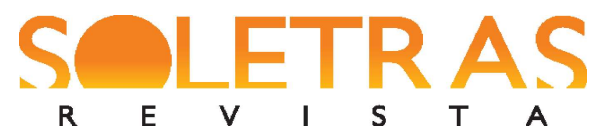

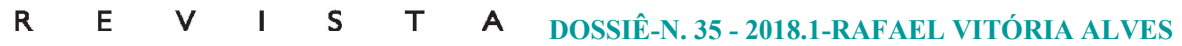

LUCIANA CABRINI SIMÕES CALVO

É importante ressaltar que, em linhas gerais, a necessidade de fornecer habilitação específica, conforme objetivo da proposta, surgiu da constatação do atual cenário brasileiro que reflete os baixos percentuais de docentes que possuem formação inicial específica na disciplina que lecionam. De acordo com o Instituto Nacional de Estudos e Pesquisas Educacionais Anísio Teixeira (INEP), no relatório produzido pela Comissão Especial (BRASIL, 2007), em algumas disciplinas, como Língua Portuguesa, Biologia e Educação Física, esse percentual é um pouco mais alto, ultrapassando 50\%. Já em outras, como Física e Química, os percentuais são extremamente preocupantes, chegando a $9 \%$ e 13\%, respectivamente.

Considerando a importância e a recente implantação desse programa, torna-se relevante investigar os seus resultados em relação à formação do professor de LI a partir da visão dos seus envolvidos. Esta pesquisa se juntará a outras investigações realizadas sobre o PARFOR nas suas diversas licenciaturas (e.g. PRATES, 2012; ARAUJO et al., 2012, LIPPO; LIPPO, 2011; PESSÔA, s.d.), para que, assim, possam "ampliar nosso conhecimento sobre esse programa emergencial de formação" e "contribuir com intervenções que se mostram necessárias" (PESSÔA, s.d., p. 1).

Contribuições específicas para a formação do docente de línguas também precisam ser evidenciadas, já que "tratar do tema da formação de professores de línguas no contexto brasileiro nos dias atuais é, por si só, um desafio" (GIMENEZ, 2005, p. 183).

Este artigo traz, então, os resultados de uma pesquisa que teve como objetivo investigar a visão de acadêmicos e formadores de uma universidade pública paranaense, envolvidos no PARFOR, a respeito da formação docente inicial de LI contemplada pelo projeto no qual estão envolvidos. De modo mais específico, essa investigação: (i) analisou como os acadêmicos e formadores do PARFOR consideram a proposta de formação do referido programa; (ii) examinou a visão dos acadêmicos do PARFOR a respeito de sua própria formação como professores de LI ao participarem das atividades contempladas no projeto do curso e (iii) investigou as considerações dos formadores envolvidos no programa em relação à formação docente inicial de LI contemplada no projeto do curso e vivenciada pelos acadêmicos. 


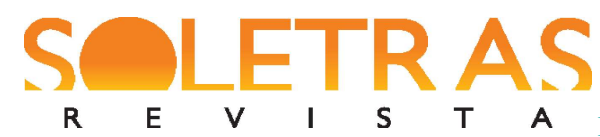

DOSSIÊ-N. 35 - 2018.1-RAFAEL VITÓRIA ALVES

LUCIANA CABRINI SIMÕES CALVO

\section{Caracterização da pesquisa e dos sujeitos}

Esta é uma pesquisa de cunho qualitativo, pois "procura entender, interpretar fenômenos sociais inseridos em um contexto" (BORTONI-RICARDO, 2008, p. 34), mas que emprega método quantitativo, de forma complementar, para determinar as frequências nas respostas, visto que "métodos quantitativos são usados na pesquisa qualitativa para servir às finalidades delimitadas pelo pesquisador" (REIS, 2006, p. 106). Ela também se caracteriza como um estudo de caso porque investiga uma unidade específica bastante delimitada, qual seja, o programa do PARFOR, na área de LI, de uma universidade pública paranaense.

O corpus do estudo é composto de questionários endereçados aos acadêmicos (Apêndice A) e formadores (Apêndice B) participantes do programa. Os questionários foramendereçados aos acadêmicos ingressantes no ano de 2012. Tivemos treze respondentes com faixa etária, na época da coleta dos dados, entre 30 a 40 anos e o tempo de atuação como professor era de 05 a 10 anos. Baseando-se nessas informações, podemos constatar que se trata de uma turma madura, com relevante experiência em sala de aula.

Em relação à formação acadêmica, nota-se uma prevalência da formação inicial na área de Letras. Em percentuais, isso resulta em 59\% do total: Letras Português (25\%), Letras Português-Espanhol (17\%), Letras Português-Inglês (9\%) e Letras Português-Francês (8\%). Tendo em vista esse resultado, é percebido que a maior parte da turma já estava inserida no contexto de ensino de línguas. Houve, entretanto, outras realidades: Pedagogia (25\%), História (8\%) e Educação Física (8\%).

No que se refere à área de atuação, apenas uma acadêmica respondeu que lecionava aulas de LI. Dessa maneira, tais informações entram em divergência com os requisitos iniciaisdo PARFOR, que determinam que a modalidade de segunda licenciatura seja voltada para "professores licenciados que estejam em exercício há pelo menos três anos na rede pública de educação básica e que atuem em área distinta da sua formação inicial"'(CAPES, 2010, p. 1), ou seja, os participantes deveriam atuar por, no mínimo, três anos na disciplina que não possuem habilitação e ministraraulas, neste caso, de LI.

Quanto ao contexto de trabalho, notamos que os acadêmicos lecionavam quase majoritariamente no ensino fundamental (nove dos treze respondentes) e em escolas públicas (dez dos treze respondentes). Em vista disso, podemos considerar que esse resultado vem ao encontro das premissas do PARFOR, já que, segundo o site da Capes (2010, p. 1, grifos nossos), o seu objetivo é "induzir e fomentar a oferta de educação 


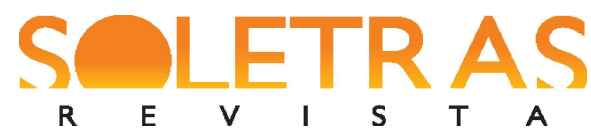

DOSSIÊ-N. 35 - 2018.1-RAFAEL VITÓRIA ALVES

LUCIANA CABRINI SIMÕES CALVO

superior, gratuita e de qualidade, para professores em exercício na rede pública de educação básica $[\ldots] "$.

Em relação aos formadores, no total, houve cinco questionários respondidos e, no que tange ao perfil deles, é perceptível a diversidade da área de atuação/especialidade tanto dentro quanto fora do PARFOR, envolvendo os campos de: Ensino, Tradução, Literatura. Há casos, ainda, de professores que lecionavam no curso de Secretariado Executivo e de Letras-Língua Portuguesa. Já o tempo de atuação no PARFOR, por se tratar de recente implantação, é praticamente igual para todos os docentes. Outro dado a ser observado é o que se refere ao nível de formação acadêmica, em que $40 \%$ dos entrevistados são mestres, $20 \%$ doutorandos e $40 \%$ doutores.

Conforme já pontuado, para a geraçãodos dados da pesquisa, foram elaborados dois questionários: um endereçado aos acadêmicos e outro aos formadores. Inicialmente, havia uma seção inicial que deveria ser preenchida com informações pessoais e profissionais, as quais foram discutidas anteriormente. $\mathrm{Na}$ sequência, foram apresentadas as questões divididas por dois blocos. O primeiro bloco foi constituído por duas perguntas comuns a acadêmicos e formadores, as quais solicitavam que esses sujeitos exprimissem opiniões e considerações com relação ao programa PARFOR enquanto proposta governamental e, também, apontassem potencialidades e limitações desse programa.

O segundo bloco, por sua vez, afunilou para o curso PARFOR Letras-Inglês implantado na IES investigada. Havia uma questão específica para o questionário dos acadêmicos, que procurou compreender os motivos que impulsionaram o ingresso no PARFOR Letras-Inglês da IES. Também havia duas questões específicas para o questionário dos formadores, que solicitavam a indicação das vantagens e desvantagens do PARFOR Letras-Inglês em comparação ao curso de graduação regular e a avaliação da grade curricular. E havia, por fim, duas perguntas comuns a acadêmicos e formadores, que requeriam que esses sujeitos avaliassem os pontos positivos e aqueles a serem revistos do curso e, também, apontassem as suas contribuições para a prática em sala de aula.

Os resultados e discussões, apresentados a seguir, serão divididos em dois tópicos, cada um referente a um dos blocos e seguindo a ordem das questões, da forma como foram mencionadas acima.

\section{A visão dos sujeitos acerca da proposta do programa PARFOR}




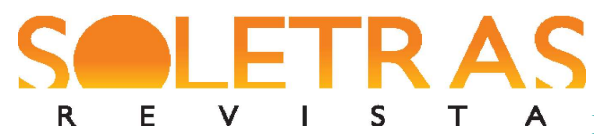

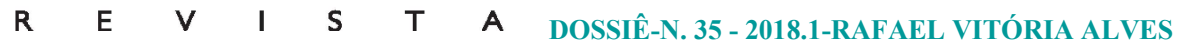

LUCIANA CABRINI SIMÕES CALVO

O propósito desta primeira etapa é refletir, sob uma óptica abrangente, a respeito dos pareceres em relação ao programa PARFOR que não se referem apenas ao curso investigado, mas ao mencionado programa enquanto uma ação política social, regulamentada por uma lei federal (PESSOA, 2014).

A primeira constatação a ser feita é com relação às opiniões expressas pelos acadêmicos acerca da proposta do programa, que são unanimemente positivas. Isso é constatado pelo emprego de palavras de caráter apreciativoque retratam o contentamento deles em relação ao referido programa. Entre elas, temos: uma oportunidade (36\%) - que se refere à oferta de ingresso em um curso de formação -, ótima $(22 \%)$, boa $(14 \%)$, interessante (14\%), eficaz (7\%) e excelente (7\%).

Como os números demonstram, conceber o programa como uma oportunidade ganhou destaque entre as respostas. Isso fica evidente no relato da acadêmica G (2013): “É uma oportunidade de os professores estudarem em uma universidade pública de qualidade. Com isso, nós podemos adquirir novos conhecimentos e melhorar nossa prática em sala de aula".

A visão dos formadores assemelha-se a dos acadêmicos, pois também usaram palavras de cunho positivo para emitir suas opiniões acerca da proposta do programa. $\mathrm{Na}$ concepção deles, a proposta é considerada interessante (60\%) e válida (40\%), no sentido de "complementar a formação de professores que já trabalham em determinadas disciplinas" (Formadora CLARA, 2014) e, além disso, promove a regularização da situação dos que não possuem habilitação específica, já que:

A ação do Programa decorre da constatação apresentada nos dados educacionais que o Brasil ainda mantém nas suas redes uma quantidade significativa de professores [...] formados em áreas distintas de sua atuação profissional na educação (PESSOA, 2014, p. 13).

Essa questão também pode ser vista no relato da formadora A (2014): "Pelo que sei, ela visa regulamentar a situação dos professores que ministravam LI sem ter essa formação".

Essas opiniões positivas, tanto de acadêmicos quanto formadores, também foram encontradas em outras pesquisas de similar teor, nas quais os pesquisadores chegaram à 


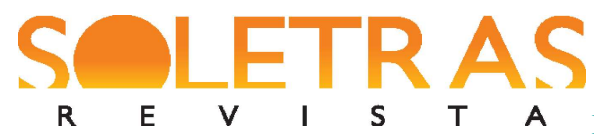

$\begin{array}{llllllll}R & \text { E } & \text { V } & \text { I } & \text { S } & \text { T } & \text { A } & \text { DOSSIÊ-N. } 35 \text { - 2018.1-RAFAEL VITÓRIA ALVES }\end{array}$

LUCIANA CABRINI SIMÕES CALVO

conclusão que "a maioria [dos sujeitos da pesquisa] afirma que o PARFOR oferece uma grande oportunidade de profissionalização" (ABDALLA, 2012, p. 7) e também que "o PARFOR [...] apresenta-se como uma oportunidade para esses professores obterem a titulação de graduação em uma instituição de qualidade e gratuita" (PAINI; COSTA, 2014, p. 34).

Ainda a respeito da primeira pergunta do questionário, além de emitir opiniões, os acadêmicos teceram considerações sobre o programa ${ }^{3}$. Uma boa parte discorreu sobre ele se caracterizar como uma formação adicional (25\%), isto é, possibilitar a obtenção de outra licenciatura, como pode ser exemplificado por meio da resposta da acadêmica F (2013, grifos nossos): “[...] uma oportunidade de conseguir a segunda graduação [...]”. É perceptível que tal resposta se relaciona intrinsicamente com a opinião geral do programa que, do ponto de vista dos sujeitos da pesquisa, é concebido como "uma oportunidade".

Além dessa resposta, foram assinaladas outras, que evidenciam que o programa proporciona: novos conhecimentos $(25 \%)$, melhoria da prática $(13 \%)$, formação de qualidade $(6 \%)$ e acesso a uma universidade estadual (6\%). Este último dado pode ser interpretado levando em consideração que algumas pessoas concedem um status mais elevado às universidades públicas.

Ainda comentando sobre as considerações, 19\% apontaram problemas com a documentação. Esse fato reflete o momento de angústia pelo qual os acadêmicos estavam passando, visto que apenas no final do curso foi solicitada a entrega de alguns documentos que comprovassem a atuação em aulas de LI, o que, segundo os alunos, foi um desencontro entre a oferta do curso e sua real implantação, isto é, a maior parte não tinha conhecimento que precisava lecionar LI pra ingressar no curso. Tendo isso em vista, o acadêmico VM (2013), assim como outros, sugere que seja deixado mais claro para quem o curso se direciona, ou seja, o público-alvo.

Apesar dessa situação específica, o resultado geral assemelha-se ao encontrado por Paini e Costa (2014), em que foi constatado que o PARFOR representa uma opção para ampliar conhecimentos e aprimorar a atuação em sala de aula, traduzindo-se numa oportunidade de aperfeiçoamento, atualização, além de promover a inclusão na LDB.

\footnotetext{
3 Ressalta-se que 6\% não teceram considerações.
} 


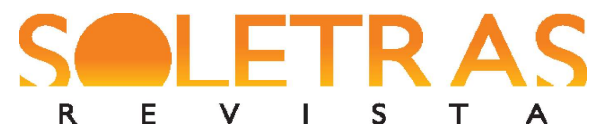

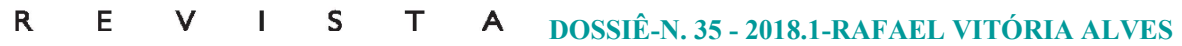

LUCIANA CABRINI SIMÕES CALVO

Além dos acadêmicos, dois formadores redigiram considerações sobre o programa ${ }^{4}$. A primeira consideração trata-se de uma crítica ao governo, pois, na opinião do formador, o PARFOR consiste em uma solução paliativa e sugere que uma possível solução definitiva seja a abertura de novos concursos para resolver a falta de professores nas escolas. A segunda formadora, por sua vez, acredita que apesar de válida, a proposta do programa é mais adequada para regiões como a norte, por exemplo.

Essa consideração pode ser articulada com relatório do PNE (2014), o qual pontua que a região norte tem apenas $45 \%$ de professores de ensino médio com a habilitação específica. Em relação ao ensino fundamental, esse mesmo relatório aponta que o Norte tem $18,1 \%$ de professores com a formação adequada para a disciplina que ministram. São porcentagens expressivas (e, de certa forma, alarmantes) que justificavam o parecer da formadora.

A segunda pergunta do questionário levou os sujeitos a pontuarem potencialidades e limitações do programa. A principal potencialidade levantada, na visão dos acadêmicos ${ }^{5}$, novamente abarca a questão do programa se constituir em uma oportunidade (29\%) para quem deseja obter uma qualificação maior, uma formação adicional, melhorar sua prática, entre outras justificativas que foram discutidas anteriormente.

Destacou-se também: a qualidade dos formadores (23\%) e a abordagem com que as disciplinas são ministradas por eles, tal qual relata a acadêmica C: "É um curso ótimo, com professores qualificados e que nos proporciona um grande aprendizado"6.

Esse resultado satisfatório em relação aos formadores leva a crer que esses, em sua maioria, estão sendo norteados pelas prerrogativas que os colocam no papel de um profissional reflexivo, comprometidos com a constante observação do contexto em que estão inseridos e suas práticas em sala de aula. Essas noções vêm sendo discutidas por pesquisadores em diversas literaturas (e.g. STURM, 2011; MOURA FILHO, 2011, entre outros).

\footnotetext{
${ }^{4}$ Informa-se que $75 \%$ não teceram considerações.

$524 \%$ dos sujeitos optaram por não responder.

${ }^{6}$ Essa questão estámais relacionada ao Bloco 2 (curso ofertado pela IES). Talvez a proposta de divisão dos blocos não tenha ficado clara para esses acadêmicos nesse momento. Independentemente, essas respostas não foram deslocadas para o próximo bloco, justamente para não comprometer a linearidade pensada para os questionários.
} 


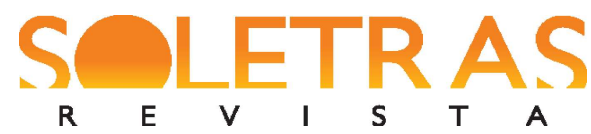

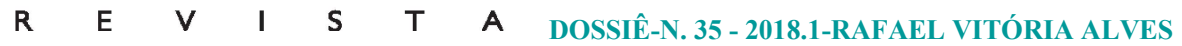

LUCIANA CABRINI SIMÕES CALVO

Ainda é mencionada a duração e a carga horária (12\%) do curso e o fato de o programa ser compatível com o perfil dos alunos (12\%). Vale ressaltar que essa última questão é pouco representativa, uma vez que, como visto anteriormente, houve um conflito entre o perfil dos alunos e a divulgação do programa.

Os formadores, por sua vez, reiteram a resposta dada pelos acadêmicos que consideram como principal potencialidade do PARFOR, novamente, a questão da oportunidade (75\%): “A principal potencialidade, em minha opinião, está relacionada à oportunidade de uma formação específica para professores que estão em sala de aula há muitos anos ministrando disciplinas que não fizeram parte de seu curso de graduação" (Formadora HELENA, 2014).

Ainda é mencionada a experiência dos alunos em sala de aula (25\%) como um fator positivo, tendo em vista que esses já estão inseridos no contexto da educação e, nesse sentido, suas experiências servem como ponto de partida para a reflexão sobre suas práticas, já que para Souza (2014, p. 81) "as experiências desses professores estudantes sempre são consideradas $[. .$.$] de modo a contribuir de maneira significativa com essa formação".$

Com relação às limitações, na percepção dos acadêmicos ${ }^{7}$, a questão da duração do curso e a carga horária foi uma das mais pontuadas $(20 \%)$, e pode ser mais bem compreendida por meio da resposta da acadêmica Linha (2013): "As limitações são a carga horária e aulas no sábado, se torna cansativo". Esse dado é contraditório, pois conforme já visto anteriormente, foi citada a mesma resposta como uma potencialidade. Dessa maneira, estabelece-se uma relação paradoxal entre os dados.

Uma tentativa de explicar o motivo para tal está centrada no fato de que a realidade pessoal de cada um pode ter influenciado na resposta, já que, para alguns, ter aulas aos sábados e feriados é uma forma de aproveitar os espaços vagos; para outros, pode representar um período a menos de convivência no seio familiar.

Tem-se também: disponibilidade de tempo para estudo (20\%), visto que os acadêmicos atuam como professores, e, portanto, já estão sobrecarregados com as obrigações que a carreira docente exige; falta de clareza nas informações (13\%) que remete ao caso das comprovações exigidas somente ao final do curso, que foram especificadas

\footnotetext{
${ }^{7}$ Ressalta-se que $27 \%$ se abstiveram de responder.
} 


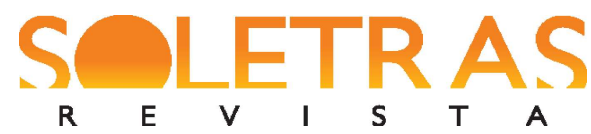

DOSSIÊ-N. 35 - 2018.1-RAFAEL VITÓRIA ALVES

LUCIANA CABRINI SIMÕES CALVO

anteriormente; falta de envolvimento em projetos (6\%); material didático e conteúdo pouco apropriados para a realidade dos alunos (7\%); e espaço de tempo sem estudo de LI (7\%), que indica uma lacuna na organização nas disciplinas do curso. Este último caso também é comentado no relato de uma formadora entrevistada na pesquisa de PÊSSOA (s.d., p. 3) sobre o PARFOR: "Quando você acha que o aluno está começando a aprender algo, você interrompe tudo e só retorna três semanas depois".

Quanto às limitações, na visão dos formadores, $50 \%$ das respostas pontuam a pouca disponibilidade dos acadêmicos para estudo extraclasse e para a realização de trabalhos/atividades. Esse fato é evidenciado no relato da formadora A: “[...] vejo que, já sendo professores, os alunos têm menos tempo de estudo em casa". As causas para isso foram discutidas acima, já que este também foi um fator mencionado pelos acadêmicos.

Outras respostas foram em relação à duração $(17 \%)$ e à carga horária $(17 \%)$ que, de igual forma, já foram discutidas em momentos anteriores, principalmente por estarem contidas tanto nas potencialidades como nas limitações na visão dos acadêmicos.

Ademais, há a questão das aulas concentradas (16\%), pois há certa preocupação sobre o tempo muito prolongado de aula, que pode tornar a aprendizagem cansativa, tal como é dito pela formadora entrevistada na investigação de PÊSSOA (s.d., p. 3) "[...] as aulas eram concentradas: 4 dias seguidos, de manhã e de tarde [...] Um dia de aula significa 10h/aula. Quem consegue aprender direito?”.

\section{A visão dos sujeitos com relação à proposta do curso PARFOR Letras-Inglês da IES}

Nesta segunda etapa, as perguntas focam exclusivamente no curso PARFOR LetrasInglês da IES em que os acadêmicos e os formadores estão envolvidos. A primeira questão, que é exclusiva dos acadêmicos, volta-se para os motivos que levaram ao ingresso no curso PARFOR Letras-Inglês. Vários motivos foram levantados, contudo, a valorização do currículo e obtenção de segunda graduação foram predominantes nas respostas $(46 \%)^{8}$. O comentário do acadêmico B (2013) resume bem essa questão: “[...] ter um aprendizado diferenciado no meu currículo".

\footnotetext{
${ }^{8}$ Os outros motivos partem de um ponto de vista muito pessoal e específico e, portanto, não carecem de discussão.
} 


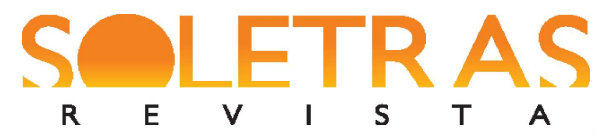

DOSSIÊ-N. 35 - 2018.1-RAFAEL VITÓRIA ALVES

LUCIANA CABRINI SIMÕES CALVO

Por um lado, a valorização do currículo, que parte da busca de novos conhecimentos, pode ser entendida como uma forma de reflexão sobre sua própria prática, já que para quem assinalou essas respostas, a oportunidade ofertada pelo PARFOR é vista como uma forma também de aprimorar a prática.

Essa afirmação alicerça-se nas discussões de Schön (2000 apud MOURA FILHO, 2011) que apregoa que a reflexão sobre a ação apoia o profissional a avançar na busca do conhecimento, e é complementado por Dutra e Mello (2004, p. 31 apud MOURA FILHO, 2011) que argumentam que "[...] a reflexão só emerge na vida de um professor, no nosso caso de línguas estrangeiras, quando há uma abertura para entendê-lo como um profissional em constante desenvolvimento e formação".

Por outro lado, pode-se inferir que essa motivação foi impulsionada pela necessidade de se obter prestígio em detrimento aos demais docentes, ao ter uma formação diferenciada dos demais e, também, visando valorizar o salário.

A segunda questão, específica dos formadores, objetiva uma reflexão sobre o PARFOR-Inglês em comparação ao curso regular. Ela reflete muito a opinião pessoal de cada docente entrevistado e as respostas giram, em sua maioria, em torno da curta duração do curso e a alocação de disciplinas no final de semana, que são os fatores principais que diferenciam o PARFOR da graduação regular. Enquanto que para alguns professores isso é visto como uma vantagem, para outros é visto como desvantagem.

A terceira questão, também exclusiva dos formadores, solicita uma avaliação da grade curricular do curso PARFOR Letras-Inglês. As respostas também geraram discrepância, visto que alguns consideram a grade adequada e outros não.

Os formadores que acreditam que a grade curricular é apropriada, embora tenham essa opinião, citam alguma ressalva, que inclui alguns aspectos, como: a carga horária de cada disciplina, a cronologia, ou seja, a ordem com que essas disciplinas são alocadas na grade curricular e, também, o distanciamento das matérias, que geralmente são trabalhadas concentradas por um período prolongado e depois ficam meses sem serem trabalhadas. Um exemplo desse tipo de resposta pode ser visto no relato da formadora Helena (2014): "Acho que a grade é adequada sim. O problema é o tempo reduzido para o desenvolvimento das atividades das disciplinas". Um parecer similar é encontrado na pesquisa de Pessoa (s.d., p. 3) em que umas das professoras entrevistadas afirma que "as aulas concentradas em noites seguidas de uma semana por mês não são boas". 


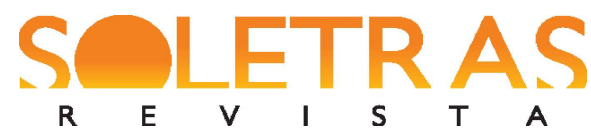

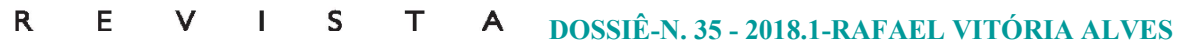

LUCIANA CABRINI SIMÕES CALVO

Os fatores relacionados acima também são vistos na argumentação dos formadores que não consideram a grade adequada para a formação dos acadêmicos. Porém, além disso, esses demonstram uma maior preocupação no que diz respeito ao pouco enfoque dado às disciplinas que priorizam o uso da LI que, conforme a opinião da formadora Clara (2014), é o que justifica a existência do curso.

A quarta questão, comum a acadêmicos e formadores, versa sobre os pontos positivos e pontos a serem revistos no PARFOR Letras-Inglês da IES. O apontamento dos pontos positivos pelos acadêmicos segue a mesma linha em todos os questionários e pode ser sintetizado pela resposta da acadêmica C (2013): "Curso ótimo, professores qualificados e ótima aprendizagem"9.

Além disso, a aprendizagem e os colegas também são ressaltados como pontos positivos e, juntamente com os formadores, caracterizam-se como elementos primordiais do processo de formação. Dessa forma, fica explícita a satisfação dos acadêmicos.

Esses dados vêm ao encontro do resultado da pesquisa de Paini e Costa (2014, p. 31) na qual é apontado que "com relação à satisfação dos alunos do PARFOR com os cursos que estão realizando na [IES], os dados expressos [...] demonstram que 97\% dos entrevistados estão satisfeitos ou muito satisfeitos".

$\mathrm{Na}$ visão dos formadores, a resposta sobre os pontos positivos é uníssona e conectase com a visão dos acadêmicos, já que também elegem o corpo docente e o curso como resposta para tal questionamento.

Já sobre os pontos a serem revistos, boa parte dos acadêmicos se absteve da resposta, sendo os únicos apontamentos: haver mais disciplinas de LI para promover um maior contato com a língua-alvo; e uma sugestão para que as disciplinas sejam melhores distribuídas. Essas questões se relacionam com a preocupação dos formadores sobre disciplinas que priorizam o contato com a língua e, também, sobre a concentração das aulas - ambas mencionadas anteriormente.

Os formadores, por sua vez, assinalam como ponto a ser revisto a questão do perfil dos acadêmicos não estar de acordo com a proposta inicial do programa, visto que de todos

\footnotetext{
${ }^{9}$ É importante atentar-se para o fato de que anteriormente o formador foi apontado como uma potencialidade do programa e, agora, como um ponto positivo do curso.
} 


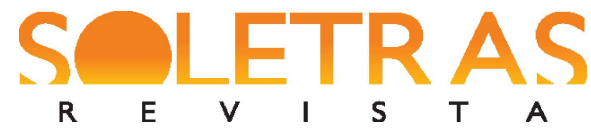

$\begin{array}{llllllll}R & \text { E } & \text { V } & \text { I } & \text { S } & \text { T } & \text { A } & \text { DOSSIÊ-N. } 35 \text { - 2018.1-RAFAEL VITÓRIA ALVES }\end{array}$

LUCIANA CABRINI SIMÕES CALVO

os acadêmicos, apenas um atende aos requisitos estipulados no edital inicial do programa, que determina a obrigatoriedade de lecionar LI há pelo menos três anos.

A última questão, que também compreende tanto a visão dos acadêmicos quanto dos formadores, é referente às contribuições do PARFOR Letras-Inglês da IES para a prática em sala de aula dos acadêmicos. As respostas dos acadêmicos, em sua totalidade, destacaram a contribuição do curso para a sua formação, ampliação de horizontes e melhoria no desempenho em sala de aula. Isso é confirmado na declaração do acadêmico A (2013) que, ao responder se o curso contribuiu com a sua formação, afirmou: "Sim. Contribuiu na vida pessoal e profissional, ampliou os conhecimentos e criou uma nova perspectiva profissional".

Além disso, todos os participantes, exceto dois, mencionaram que já articulam o que aprenderam no curso com a sala de aula. Alguns, ainda, especificaram em quais aspectos, como o acadêmico C (2013), que ressalta a questão das dinâmicas de leitura, pois aprendeu a aprimorar sua "busca por conteúdo mais prazeroso aos alunos."

Outras pesquisas também destacam as contribuições do PARFOR, no sentido de que “[...] alguns professores/alunos revelam que o curso serviu como incentivo para continuarem estudando" (SOUZA, 2014, p. 91) e também que “[...] a experiência do professor, acrescida ao suporte teórico que o PARFOR oferece, contribui para a capacitação profissional" (PAINI; COSTA, 2014, p.34).

Com relação à visão dos formadores, todos destacaram que o PARFOR Letras-Inglês contribuiu com a formação dos acadêmicos, no sentido de que o curso deu a eles um espaço para que pudessem refletir sobre a própria prática docente.

Todavia, considerando o fato de que a realidade dos acadêmicos é divergente da proposta inicial, isto é, a maioria da turma não lecionava LI no contexto escolar, uma formadora preocupa-se que o curso, embora tenha cumprido um papel importante na formação dos participantes, não tenha sido suficiente para torná-los proficientes na língua que ensinarão.

\section{Considerações finais}

Neste trabalho, procuramos investigar o PARFOR, enquanto programa de formação de professores, tendo como base o ponto de vista dos formadores e acadêmicos envolvidos, 


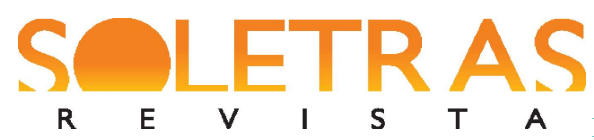

DOSSIÊ-N. 35 - 2018.1-RAFAEL VITÓRIA ALVES

LUCIANA CABRINI SIMÕES CALVO

levando em consideração seus pareceres a respeito da proposta do referido programa e, de forma específica, do curso investigado.

Diante do que foi proposto, com base nas discussões, podemos pontuar que o programa PARFOR caracterizou-se como uma oportunidade para que acadêmicos pudessem repensar suas práticas, valorizar o currículo, obter novos conhecimentos, ter acesso a uma universidade pública, entre outros benefícios. Embora haja algumas questões como carga horária e organização das disciplinas que dividem opiniões, de forma geral, o curso é bem avaliado pelos sujeitos, com destaque para o corpo docente. Assim, constata-se que, no contexto desta pesquisa, a política pública adotada para criação do programa repercutiu de forma positiva e satisfatória para os seus participantes.

Contudo, houve um desencontro entre o perfil dos acadêmicos ingressantes e as exigências especificadas no edital, pois, de acordo com acadêmicos, essas não ficaram claras na divulgação, de modo que tal situação configurou-se como um ponto reticente do curso investigado.

Levando isso em consideração, pode ser interessante que os órgãos governamentais considerem uma ampliação do edital para abranger outras realidades de ingresso para atender formandos em licenciaturas com áreas afins, principalmente se pensarmos no curso de Letras com suas várias habilitações, o que pode tornar a proposta mais interessante, visto que disponibilizará vagas compatíveis com outros perfis docentes, especialmente no campo das linguagens. Dessa maneira, sua contribuição com a melhoria do ensino básico do país tende a aumentar, visto que irá oportunizar uma formação adicional para uma parcela ainda maior de professores que atuam nessa rede de ensino.

\section{Referências bibliográficas}

ABDALLA, M. F. B. Das implicações da política de formação de professores (PARFOR): entre desafios e proposições. In: ENCONTRO NACIONAL DE DIDÁTICA E PRÁTICA DE ENSINO, 16. 2012, Campinas. Anais... Campinas: Unicamp, 2012.

ARAUJO, C. R. P. et al. Análise crítica do PARFOR enquanto propósito e realidade no cariri cearense. In: ENCONTRO NACIONAL DE DIDÁTICA E PRÁTICAS DE ENSINO, 16. 2012, Campinas. Anais... Campinas: Unicamp, 2012.

BORTONI-RICARDO, S. M. O professor pesquisador: introdução à pesquisa qualitativa. São Paulo: Parábola, 2008. 


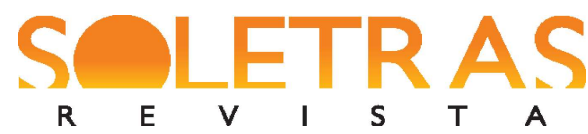

DOSSIÊ-N. 35 - 2018.1-RAFAEL VITÓRIA ALVES

LUCIANA CABRINI SIMÕES CALVO

BRASIL. Conselho Nacional de Educação/Câmara de Educação Básica. Escassez de professores no Ensino Médio: propostas estruturais e emergenciais. Relatório produzido pela Comissão Especial instituída para estudar medidas que visem a superar o déficit docente no Ensino Médio. Brasília, DF, mai. 2007. Disponível em:

$<$ http://portal.mec.gov.br/cne/arquivos/pdf/escassez1.pdf $>$. Acesso em: 01 maio 2018.

BRASIL. Decreto n. 6.755, de 29 de janeiro de 2009. Institui a Política Nacional de Formação de Profissionais do Magistério da Educação Básica, disciplina a atuação da Coordenação de Aperfeiçoamento de Pessoal de Nível Superior - CAPES no fomento a programas de formação inicial e continuada, e dá outras providências. Diário Oficial da União, Brasília, DF, jan. 2009.

BRASIL. Ministério da Educação. Coordenação de Aperfeiçoamento de Pessoal de Nível Superior. Plano Nacional de Formação de Professores da Educação Básica - PARFOR. Brasília: 2010. Disponível em: <http://www.capes.gov.br/educacao-basica/PARFOR>. Acessoem: 22 ago. 2013.

GATTI, Bernardete A. et al. A Atratividade da Carreira Docente no Brasil; relatório de pesquisa- versão preliminar. São Paulo: Fundação Carlos Chagas; Fundação Vitor Civita, 2009.

GIMENEZ, T. Desafios contemporâneos na formação de professores de línguas: contribuições da linguística aplicada. In: FREIRE, M. M.; ABRAHÃO, M. H. V.; BARCELOS, A. M. F. (Org.). Linguística Aplicada e contemporaneidade. Campinas: Pontes, 2005.

LIPPO, B. R. S; LIPPO, P. C. S. Alunos do Plano Nacional de Formação de Professores da Educação Básica (PARFOR): professores "polivalentes" inclusive de educação física. In: COLÓQUIO INTERNACIONAL "EDUCAÇÃO E CONTEMPORANEIDADE”, 5, 2011, São Cristovão. Anais... São Cristovão, 2011.

MOURA FILHO, A. C. L. Basta de clamarmos por inocência: A Formação Reflexiva do Professor Contemporâneo de Línguas. In: SILVA, K. A. da, DANIEL, F. de G., KANEKOMARQUES, S. M., SALOMÃO, A. C. B. (Org.). A Formação de Professores de Línguas: novos olhares - volume I. Campinas: Pontes Editores, 2011.

PAINI, L. D; COSTA, C. E. M. A Formação de Professores em Debate: integração da universidade com o ensino básico. In: PAINI, L.D.; COSTA, C.E.M.; VICENTINI, M.R. (Org). PARFOR: Integração entre Universidade e Ensino Básico diante dos desafios na formação de professores do Paraná. Maringá: Eduem, 2014.

PESSÔA, A. R. Formação de Professores de Inglês em Cursos de Letras - PARFOR. Disponível em: <www.letras.ufg.br/uploads/25/original_VIISLE_14.pdf>. Acesso em: 22 ago. 2013. 
PESSOA, I. L. Apresentação. In: PAINI, L.D.; COSTA, C.E.M.; VICENTINI, M.R. (Org). PARFOR: Integração entre Universidade e Ensino Básico diante dos desafios na formação de professores do Paraná. Maringá: Eduem, 2014.

PNE. Observatório do PNE. 2014. Disponível em <http://www.observatoriodopne.org.br/> Acesso em: 10 out. 2014.

PRATES, D. C. PARFOR: um espaço de formação carregado de sentidos e significados a constituir o ser e o fazer docente. In: SEMINÁRIO DE PESQUISA EM EDUCAÇÃO DA REGIÃO SUL, 9., 2012. Anais... Caxias do Sul: UCS, 2012.

PROJETO PEDAGÓGICO. Programa Emergencial para Formação de Professores em Exercício na Educação Básica Pública - Segunda Licenciatura - Inglês - Presencial. Departamento de Letras, Universidade Estadual de Maringá, 2011.

REIS, S. Reflexões sobre uma jornada com destino à pesquisa. Revista Brasileira de Linguística Aplicada, v. 6, n. 1, 2006.

SOUZA, M. I. P. O. A Formação de professores no PARFOR: construindo conceitos e revendo paradigmas. In: PAINI, L.D.; COSTA, C.E.M.; VICENTINI, M.R. (Org.). PARFOR: Integração entre Universidade e Ensino Básico diante dos desafios na formação de professores do Paraná. Maringá: Eduem, 2014.

STURM, L. Conhecendo a realidade escolar para uma formação reflexiva do professor de inglês. In: SILVA, K. A. da, DANIEL, F. de G., KANEKO-MARQUES, S. M., SALOMÃO, A. C. B. (Org.) A Formação de Professores de Línguas: novos olhares - volume I. Campinas: Pontes Editores, 2011.

\title{
Government programs of teacher education: a look at the PARFOR-English of a public university in Paraná
}

\begin{abstract}
This article presents the results of a research that focused on the National Teacher Education Plan for Basic Education (PARFOR), specifically in one English language course of a public institution of higher education in Paraná. The aim of this study was to analyze the view of students and professors involved in the program regarding the initial teacher education of English Language proposed in the mentioned course/project, promoting articulations with other studies that focus on teacher education. This is a qualitative research, using quantitative method for part of the data analysis. The study is also considered a case study. The corpus of the research was composed of questionnaires addressed to the students (from the academic year of 2012) and professors participating in the project. The results showed that the program was very important to those involved and represented an opportunity for students to rethink their practices as teachers. However, the fact that most of them did not work as teachers of English led to disagreement with the profile specified in the public notice and was thus characterized as a reticent aspect of the investigated course. As this research is related to the area of teacher education, it is hoped to contribute to the area when investigating an emergency governmental proposal of teacher education.
\end{abstract}

Keywords: PARFOR. Teacher education. English Language. 


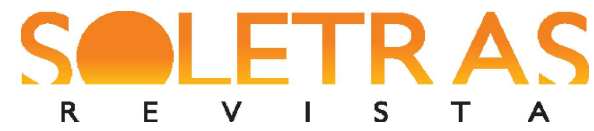

$\mathrm{s}$

Recebido em 15 de dezembro de 2017.

Aprovado em 09 de maio de 2018.

\title{
Apêndices
}

\section{Apêndice A - Questionário endereçado aos acadêmicos}

\author{
Nome da IES ${ }^{10}$ \\ DLM - Departamento de Letras Modernas
}

Prezado/a discente,

Tendo em vista uma pesquisa de iniciação científica que estamos realizando sobre o Plano Nacional de Formação de Professores da Educação Básica (PARFOR), gostaríamos de contar com a sua colaboração respondendo ao questionário que segue. Ressaltamos que ele será utilizado apenas para o fim da nossa pesquisa. Sendo assim, com o intuito de assegurar o seu anonimato, solicitamos que indique um pseudônimo para posteriormente organizarmos as respostas.

Agradecemos a sua colaboração.

Rafael Vitoria Alves (rafaelalves92@gmail.com)

Luciana Cabrini Simões Calvo (Orientadora-cabrinisimoes@gmail.com)

Informações pessoais e profissionais

Pseudônimo:

Idade:

Tempo de atuação em sala de aula:

Formação acadêmica:

Área de atuação:

Contexto de trabalho:

\section{Questões sobre o PARFOR}

\section{A - Questões sobre a proposta governamental do PARFOR}

1. Qual a sua opinião a respeito da proposta do PARFOR? Teça considerações, se necessário.

\footnotetext{
${ }^{10} \mathrm{O}$ nome da universidade, em todos os locais em que aparecia nos questionários, foi substituído por IES.
} 
2. Quais seriam, na sua visão, as potencialidades e as limitações deste programa?

B - Questões sobre o PARFOR-Letras-Inglês-IES

3. Por que você decidiu se inscrever no PARFOR-Letras-Inglês da IES?

4. Quais seriam, na sua opinião, os pontos positivos e os pontos a serem revistos no PARFORLetras-Inglês da IES?

5. Você acredita que a sua participação no PARFOR-Letras-Inglês-IES tem contribuído para a sua prática profissional como professor(a)? De que forma?

\section{Apêndice B - Questionário endereçado aos formadores}

Nome da IES

DLM - Departamento de Letras Modernas

Prezado/a docente,

Tendo em vista uma pesquisa de iniciação científica que estamos realizando sobre o Plano Nacional de Formação de Professores da Educação Básica (PARFOR), gostaríamos de contar com a sua colaboração respondendo ao questionário que segue. Ressaltamos que ele será utilizado apenas para o fim da nossa pesquisa. Sendo assim, com o intuito de assegurar o seu anonimato, solicitamos que indique um pseudônimo para posteriormente organizarmos as respostas.

Agradecemos a sua colaboração.

Rafael Vitoria Alves (rafaelalves92@gmail.com)

Luciana Cabrini Simões Calvo (Orientadora - cabrinisimoes@gmail.com)

\section{Informações pessoais e profissionais}

Pseudônimo:

Idade:

Formação acadêmica:

Área de atuação fora do PARFOR:

Contexto de trabalho fora do PARFOR:

Tempo de atuação no PARFOR:

Tempo de atuação em sala de aula:

Disciplinas ministradas no PARFOR:

Disciplinas ministradas fora do PARFOR:

Questões sobre o PARFOR

SOLETRAS - Revista do Programa de Pós-Graduação em Letras e Linguística - PPLIN 
A - Questões sobre a proposta governamental do PARFOR

1. Qual a sua opinião a respeito da proposta do PARFOR? Teça considerações, se necessário.

2. Quais seriam, na sua visão, as potencialidades e as limitações deste Programa?

\section{B - Questões sobre o PARFOR-Letras-Inglês-IES}

3. Em seu ponto de vista, quais são as principais desvantagens/carências do PARFOR em relação a um curso de Letras regular? E as vantagens?

4. Você acredita que a grade curricular oferecida pelo PARFOR-Letras-Inglês-IES é adequada para a formação dos participantes? Se não, quais seriam as suas sugestões para inclusão ou exclusão de disciplinas?

5. Quais seriam, na sua opinião, os pontos positivos e os pontos a serem revistos no PARFORLetras-Inglês da IES?

6. Você acredita o PARFOR-Letras-Inglês-IES tem contribuído para a prática profissional dos participantes? De que forma isso pode ser percebido durante as aulas? 